\title{
Preferences for Political Coalitions in Spain
}

\author{
Albert Falcó-Gimeno \\ University of Barcelona \\ afalcogimeno@ub.edu
}

This is a preprint (before peer-review process) of an article submitted for consideration in South European Society and Politics published in 2012, vol.17 n.3 pp.487-502, (C) Taylor \& Francis, South European Society and Politics. The final version of the article (which is different from this one) is available online at: http://www.tandfonline.com/doi/abs/10.1080/13608746.2012.701900

\begin{abstract}
At the national level, Spain has not witnessed the formation of any coalition government yet. Spanish parties evaluate whether or not to close deals with other parties for a number of reasons, and the coalition preferences of their voters are likely to be one of them. This work explores to what extent party preferences and ideological proximity in the two main dimensions of political competition in Spain (left-right and preferences for decentralization) affect voters' coalition preferences. Using survey data from 2009, we show that self-placement in the left-right and decentralization axes and party preferences largely determine whether voters prefer single-party absolute majorities or not, whereas the determinants of the generic preference between a coalition cabinet and a single-party minority are less clear. Also, we find that specific coalition preferences are greatly affected by ideological proximity especially in the left-right axis, whereas the dimension regarding the territorial organization of the state happens to be much more salient for the supporters of regionalist parties.
\end{abstract}




\section{Introduction}

Democracy in Spain is over 30 years old, and none of its ten legislative terms has seen the formation of a coalition government. However, more than half of the cabinets have been singleparty minority governments (six out of ten). Spaniards, then, have a great deal of experience in seeing inter-party agreements at the legislative arena in order to pass laws. Besides, coalition cabinets in the regional arena (governments of the autonomous communities) are the norm rather than the exception. Hence, Spanish voters are familiar with coalitions and more generally with deals between parties but at the same time coalition governments at the national arena have been absent up to this date.

Several authors have addressed the question why this has been the case. Some claim that the fact that coalition governments do not form in Spain respond to the strategic incentives of parties. For instance, Reniu (2001) and Reniu and Bergman (2003) argue that the "coalitional resistances” of Spanish political parties are not due to an intrinsic rejection to being members of coalition governments per se, but rather to the rational calculus of Non-State-Wide Parties (NSWPs) when evaluating different goals. ${ }^{1}$ First, their estimation of the political influence they can have sitting in the opposition benches. Second, the consequences for intra-party cohesion. And last but not least, their vote-seeking objectives taking future elections into account in the national as well as in the regional arenas.

These claims go well in line with Strom's $(1984,1990)$ consideration of minority governments as rational solutions given certain conditions. In the case of Spain, opposition parties can exercise enough policy influence and at the same time avoid the attrition resulting from being a member of the government. Similarly, Müller and Strom (1999) argue that often times parties forgo immediate office-seeking goals in exchange for future vote-seeking benefits. ${ }^{2}$ For all these reasons, Spanish single-party minority governments appear to emerge as rational outcomes.

\footnotetext{
${ }^{1}$ The terms "coalitional resistances" and "Non-State-Wide Parties (NSWPs)" come from the Spanish resistencias coalicionales and Partidos de Ámbito No Estatal (PANEs), respectively.

${ }^{2}$ In another direction, Debus (2009) argues that parties usually reject some particular coalitions a priori due to the 'pariah-status' of 'anti-system' parties, although this does not seem to be relevant in the Spanish parliament.
} 
But note that the vote-seeking argument in particular seems to have a built-in assumption that is not made explicit. And that is one regarding the reaction of voters to inter-party agreements. If parties are willing to remain in the opposition without tasting the sweet flavour of cabinet offices it is because they anticipate, among others, the response of voters. If parties trade office for votes, it must be because voters would react badly to certain coalitional behaviours. But although voters seem to be a relevant actor in this story, it is not clear at all which are their reactions to potential or actual coalitions and the reasons underlying them.

In this work we want to investigate this issue in the case of Spain. We will first examine which is the general influence of party preferences on coalition preferences. That is, we will analyze whether having voted for a certain party affects what type of government Spanish voters prefer and which specific coalitions they support or oppose. Also, we will consider if there are further elements that help voters make up their minds about these preferences. Second, we will investigate the role of ideological proximity in the two traditional axes of party competition in Spain on voters' preferences for coalitions between parties. We will also zoom in on different groups of party supporters to evaluate which ideological dimension weighs more in their building of coalition preferences. That is, in a multidimensional space of political competition potential coalitions can be far in one axis but close in another one, and that requires voters to decide which dimension is more salient for them in order to support or to oppose a given interparty agreement.

The remainder of this paper is organized as follows. The next section reviews the state of the art in the research on voters' coalition preferences. In section three we present what are our ex ante expectations regarding i) what types of governments should voters prefer based on their party preferences and ii) what should be the importance of ideological proximity in the left-right and decentralization dimensions on Spanish voters' assessment of potential coalitions. Section four describes the data and variables used in the empirical analyses presented and discussed in the fifth section. Finally, the last section summarizes the main findings and offers some concluding remarks. 


\section{Coalition Preferences: What Do We Know?}

Parliamentary systems are prevalent all over Western Europe. Elections in these systems can produce a clear winner who controls the absolute majority of seats and who is able to form a single-party majority government. But most often different parties need to close deals with each other to reach the $50 \%$ seat share threshold and therefore be able to pass laws and make policy more generally. These deals can take the form of a coalition government or policy-specific agreements between opposition parties and the minority government in office.

Although these sorts of inter-party pacts are extremely frequent in multiparty parliamentary systems, we still know fairly little about what voters think about them. Clearly, parties accept or reject coalitions for reasons beyond the reaction of the electorate yet, presumably, they also pay attention to what their voters think about them. It is hence surprising that "[w]orks on coalition formation and survival have traditionally focused on tactical and policy considerations at the elite level, and frequently neglected the role of voters" (Jou 2010). As a result, the very notion of voters' coalition preferences has received scant attention in previous political science research.

In the last few years several studies have emphasized the role of coalition preferences in predicting voting behaviour. According to Kedar (2005) voters can and do often take an outcome-oriented behaviour sacrificing the party choice that is closest to their own position and opting for another party in order to make the formation of their preferred coalition more likely. Evidence has been provided for the independent role of coalition preferences on voters' behaviour for countries like Austria (Meffert and Gschwend 2008), Belgium (Gschwend and Hooghe 2008), Israel (Bargsted and Kedar 2009, Blais et al. 2006), or The Netherlands (Bäck and Rosema 2008; Irwin and Van Holsteyn 2003). However, the dependent variable for these studies is still party choice and not coalition preferences.

Also, Jou (2010) concentrates on how policy preferences of voters constrain parties' coalition choices and affect their subsequent electoral performance in New Zealand and Japan. Nonetheless, this author does not look directly to voters' coalition preferences as such and the 
main aim of his study is to understand parties' coalitional strategies and not voters' coalition tastes.

Hence, the more basic question of what determines coalition preferences in the first place (that is, taking them as the dependent variable) has seldom been addressed. But do voters have coalition preferences? Are they even objects that voters are able to evaluate? In a spatial scenario, voters place themselves in different dimensions. From a proximity perspective, they should then rank their preferences with regard to parties and coalitions: the closer ones in the first positions, those farther apart, last. But that assumes that voters are able to identify the location of the objects to be ranked. For parties, the problem is not so serious. Parties are the centre of the political life. They are the objects to which public media pay attention to. Voters receive information over their positions and platforms in campaign but also during the legislative term. For coalitions, though, the situation is more ambiguous.

Except in very concrete cases, coalitions are hypothetical constructs with positions and characteristics that are not immediately retrievable by voters. Voters' views on coalitions may be merely derived from the views on their individual members. If so, the location of a coalition in a spatial scenario would reflect some kind of compromise midpoint between the member parties, most likely weighted by the size of each one (Meffert et al. 2009). But there can be other factors that help us explain why some coalitions are preferred over others.

The study of the predictors of coalition preferences dates back to Norpoth (1980) who analyzed the preferences of the (West) German public with respect to the coalitions formed by party leaders during the 1961-76 period. Almost 20 years later, Thurner and Pappi (1999) also took the German case and addressed the question of whether or not coalition preferences mirrored party and candidate preferences. However, they did so only in passing since their main goal was to analyze voters' choice at election polls rather than coalition preferences themselves.

Very few other studies have inquired about the explanatory factors behind voters' preferences for coalitions. In one of these few, Meffert et al. (2009) found that the party preferences of Austrian voters precede their coalition preferences since a longer time is spent to answer those survey 
questions related to the latter. Nonetheless, they also claimed that coalition preferences are more than just weighted averages of party preferences. They conclude that party preferences are indeed the most important predictors of preferences for pacts, but they explain only a rather limited amount of the variance. Candidate evaluations also seem to play a remarkable role, whereas quite surprisingly, ideological and policy-based explanations largely fail to provide any further explanation. They conclude with a claim for future research that the present work tries to take over:

\begin{abstract}
The considerable unexplained variance rather suggests that other factors must play a role as well that were not captured in the analysis. But most important, it implies that coalition preferences are to a considerable degree independent of party preferences and a unique and necessary predictor of vote decisions. The challenge to future research is clear. Not only have these findings to be replicated for other countries with multiparty systems, but better explanations about the sources and origins of coalition preferences are necessary. (Meffert et al. 2009: 14)
\end{abstract}

An interesting scenario to do that is precisely one in which no formal coalition governments have formed, such as Spain. It is true that if voters' evaluation of abstract constructs like coalitions is difficult in most party systems, that should be even more complex in a country like Spain. ${ }^{3}$ But as said, Spanish voters are extremely familiar with inter-party agreements and also with coalition cabinets at regional levels. It remains intriguing, though, why these governments have not formed at the national level. Knowing more about which would be the attitudes of voters towards them could provide clues for our better understanding of Spanish (non-) coalitions. This is what this paper aims at.

\footnotetext{
${ }^{3}$ González et al. (2008) argue that in countries like Chile attitudes toward coalitions could be even more salient and predictive of party preferences since the former tend to be stable, enduring, and effectively form two relevant opposing blocks (which could be also applied to the case of Italy in certain years). However, in the vast majority of multiparty systems they are likely to be less salient, unless they exist as current or very recent governments. Clearly, the case of Spain would not fit in these criteria.
} 


\section{Coalition Preferences in Spain: What Should We Expect?}

The political space in Spain is traditionally characterized by the presence of two dimensions of electoral competition. To the traditional left-right dimension one has to add a second axis regarding the territorial organization of the state: more centralized vs. more decentralized. Obviously, voters and parties place themselves in more dimensions since there are issues that fall beyond the scope of any of the two. Nevertheless these two are the ones that better reflect the Spanish political space and can also be considered to serve as a heuristic for many other issues.

The placement of the Spanish political parties in this two-dimensional space can be identified in a number of ways, one being how voters view them. Figure 1 shows the positions of PSOE, PP, $\mathrm{IU},{ }^{4}$ and the most relevant regionalist parties in these two political axes, ranging from 0 to 10 , according to Spanish voters in 2009. ${ }^{5}$ Although the ideological variation across Spanish regionalist parties is remarkable, we only graph the placement of the regionalist parties $\mathrm{CiU}$, ERC and PNV for presentational purposes. ${ }^{6}$

\footnotetext{
${ }^{4}$ PSOE refers to the mainstream largest Spanish social-democratic party (Partido Socialista Obrero Español). PP is the largest conservative party (Partido Popular). The acronym IU stands for Izquierda Unida, the leftist nationwide party (former communist party).

${ }^{5}$ Averages weighted by territorial representativity in the survey. Data coming from the 2799 study of the Spanish Centro de Investigaciones Sociológicas (CIS), a survey conducted in April 2009, roughly a year after PSOE’s victory in legislative elections and its formation of a single-party minority government. The survey questions for the self-placement of interviewees in the two axes are the following (translated from Spanish): i) "When one talks about politics, the terms left and right are used. In this card there is a series of boxes going from left to right. In which box would you place yourself [and then a card with boxes going from 0 to 10 from left to right is shown to the respondent for her answer]. And in which box from that same scale would you place party...”. 2) "A state can organize territorially in several different ways. If in a given scale 0 represents 'maximum centralism' and 10 represents 'maximum decentralization' including the possibility of independence for the regions wanting it, in which position would you like Spain to be located? And in that same scale, in which position would you place the party...”.

${ }^{6} \mathrm{CiU}$ and ERC are two Catalan parties, the former considered to be center to center-right and the latter to be leftwing (acronyms standing for Convergència i Unió and Esquerra Republicana de Catalunya, respectively). PNV (Partido Nacionalista Vasco) is the largest regionalist party in the Basque Country typically considered to be Christian-democratic and center-right.
} 
The circles represent the averages of parties' attributed placements, which seem to be rather consistent with conventional wisdom, at least from the perspective of the resulting rankorderings. IU is the leftist statewide party, followed the regionalist ERC, by the center-left PSOE, and then the conservative PP, with the two largest regionalist parties (CiU and PNV) more or less in between the latter two. On the axis referring to the territorial organization of the state, the PP appears as the most pro-centralization, followed by the PSOE and IU. The regionalist parties obviously emerge as the most pro-decentralization.

Given the positions of Spanish political parties in the two main dimensions of political competition in the country, we can rather easily imagine which would be the placement of the coalitions that could credibly form in Spain. ${ }^{7}$ Considering coalitions as the sum of their forming parts, we should logically expect the location of the potential coalitions in this two-dimensional space to be consistent with that of their member parties. Hence, the political space of Spanish (credible) coalitions in each axis would look somewhat like what the triangles convey:

\section{[FIGURE 1 ABOUT HERE]}

These mean locations are simply the result of averaging the placement attributed by the interviewees to each potential partner. This is overall a rough assessment of the spatial location of coalitions in the two main axes of political competition in Spain, but at least from an ordinal point of view the resulting placements reflect what most of Spanish voters would think about these coalitions.

\footnotetext{
${ }^{7}$ The potential coalitions do not include PP-IU because it is not a credible governmental agreement at all. Also, the party Unión Progreso y Democracia (UPyD) is left out in all the analyses due to the reduced number of cases in which the preferred coalition was either a PSOE-UPyD or a PP-UPyD one, and above all the very small number of 2008 vote recalls for UPyD and identifications with that newly created party (founded in 2007, liberal in the leftright dimension and pro-territorial centralization). It is also worth mentioning that the coalition of the two main parties PSOE-PP is rather unlikely, but we can interpret support for this coalition as support for any of these two parties in government to give priority to pacts, deals, and agreements in legislative policy-making with one another rather than with other parties. Hereafter, the concept coalition refers to any inter-party agreement, either governmental or not.
} 
Given this spatial illustration and also that the only possibility for a single-party government to form would be an office run by either the PSOE or the PP, we can now present what we expect about the coalition preferences of Spanish voters. First, regarding the preferences for the generic type of government, we could say the following: ${ }^{8}$

$I U$ voters would i) prefer a single party not to win the absolute majority of seats in parliament (namely, they would like to avoid a single-party majority government by the PSOE or the PP). But ii) it is not so clear whether they would prefer a coalition or a single-party minority government in generic terms. The latter would clearly depend on the specific coalition being formed. Therefore, generically, IU voters are not expected to have any clear preference for a coalition government.

PSOE voters would prefer a single party to win the absolute majority of seats in parliament only if the winning party was the PSOE, but not if it was the PP. Hence, i) PSOE voters' generic preferences for single-party majority governments as opposed to single-party minority or coalition offices have no clear direction. ii) As for the dilemma between the latter two, the answer would again depend on who would be the leading party. If it was the PSOE, then a single-party minority government would be preferred as it would leave the party in the best position to negotiate with the rest of parties depending on the specific policy. Conversely, though, any PP-led coalition would probably be better than a single-party PP government from the PSOE voters' view.

For $P P$ voters, the situation would be very similar. i) No clear preference regarding a singleparty majority vs. a minority or a coalition government, and ii) no clear preference regarding what type government should form if no single-party obtained the absolute majority of seats, either a multiparty cabinet or a single-party one. Just like with PSOE voters, then, the preferences for the type of government are too context-specific to derive a clear-cut expectation.

\footnotetext{
${ }^{8}$ Assuming that voters want the government to be as close as possible to the ideological positioning of their parties (i.e. the one they have opted for in the last elections).
} 
For the voters of regionalist parties, it is rather clear that i) they would prefer no party (i.e. PSOE or PP) to win the absolute majority of seats since that would give their parties no opportunity to influence policy-making at all. Regarding the second choice between a coalition and a singleparty minority government, regionalist voters would prefer one or the other depending on the specific coalition. CiU and PNV may benefit more from a PP or a PSOE minority government rather than a PSOE-IU coalition or a PSOE-PP one, while ERC voters would more clearly prefer any coalition except an agreement between the two main parties.

Any further pattern emerging in the empirical analyses may respond to which coalitions voters believe are more likely to form (which would make it clearer whether a coalition or a singleparty minority government is preferable) or to other more generic tastes for or against specific types of governments that are not observable either. For instance, a single-party minority government could be preferred because of their tendency to offer median policy outcomes in each dimension or less preferred because of their higher instability. None of this, though, can be captured by the data we count on.

Beyond generic preferences, this paper will also look at what specific coalitions Spanish voters prefer. First, simply looking at the party choice of voters, we can expect the preferred coalitions (among the menu of credible coalitions in Figure 1) to be the following: ${ }^{9}$

\section{[TABLE 1 ABOUT HERE]}

The expectations summarized in Table 1 are derived from a proximity perspective, where one assumes that voters would opt for the alternative closest to its own spatial placement. For the doubtful cases (IU and ERC voters when PP is the formateur), the two specified alternatives are almost at an equal distance to the placement of their own party. For instance, ERC voters may prefer the average PP-REG. coalition from the point of view of the decentralization dimension, but a PP-PSOE would be closer to ERC's position in the left-right axis. Obviously, the concrete

\footnotetext{
${ }^{9}$ The preferences for single-party minority governments of the voters of the two main parties assume that this is the type of cabinet that probably leaves their party most room to pursue its desired policies, closing deals with this or that partner, depending on the specific policy and circumstances.
} 
choice would depend on which dimension was more salient for each voter. We will address the dimension saliency issue below.

It bears mentioning that these are "on average” expectations. It is clear that not all voters of a given party hold the same ideological position and it is neither the case that all of them would place each coalition in the same point. We have thus derived the expectations on voters' coalition preferences from the attributed placement of their respective parties and the average position of the coalitions. Nonetheless, to evaluate the importance of ideological proximity on the coalition preferences of Spanish voters, we also take an individual-level perspective.

More concretely, we first expect that the farther a given voter places a specific coalition from herself, the less likely she is to prefer that coalition. This should be true for the two main axes of political competition. However, an open question would be (the proximity to) which of the two dimensions matters more for coalition preferences. As said, both the traditional left-right dimension and the one regarding the territorial organization of the state are clearly prevalent in the political debate. However, some have found that while the traditional left-right dimension matters for all Spaniards when it comes the time to cast their ballot at the polls -regardless of their partisanship- the decentralization dimension is only relevant for regionalist partisans (Aguilar and Sánchez-Cuenca 2008). One could easily apply this rationale to the sphere of coalition preferences and hypothesize that while proximity in the left-right axis is going to matter for all Spanish voters, proximity in the decentralization one will only be relevant for the voters of regionalist parties.

A more conservative approach would simply expect that for all voters but regionalists, the leftright dimension will be more salient than the decentralization one in their assessment of coalition alternatives, while for regionalists both dimensions would be equally important.

\section{Data, Variables, and Methods}


In this empirical study there are mainly two dependent variables. The first one regards the preferences of Spanish voters for the generic type of government, while the second refers to preferences for coalitions between specific parties. For the analysis of the electorate's generic preferences for types of government, we use one of the questions of the survey that asks whether the respondent prefers a party winning the absolute majority of seats or not and, if the latter, whether the preferred alternative would be a single-party minority government or a coalition cabinet. ${ }^{10}$ As a result, we run two separate probit regressions: one taking the dichotomous choice between single-party absolute majority and not, and another considering the dichotomy between a coalition and a single-party minority government.

The second dependent variable of this study is voters' preferences for specific coalitions. Its operationalization is based on two questions. The first asks the following: "If general elections were to be held tomorrow and they were won by the PSOE without absolute majority, which of the following alternatives would you prefer?" ${ }^{11}$ And then the choice set is composed of i) PSOE governing in coalition with IU, ii) PSOE governing in coalition with UPyD, iii) PSOE governing in coalition with regionalist parties, iv) PSOE governing in coalition with PP, v) PSOE governing alone, and then the usual don't know, don't answer options. The same goes for the

\footnotetext{
${ }^{10}$ The exact wording is the following (translated from Spanish): "With which of the following statements do you agree more? i) The best option for a country is that one single party wins the elections with the absolute majority of seats or ii) The best option for a country is that no single party wins the elections with the absolute majority of seats". And then, for those who chose the latter, "And which of these two options do you prefer if the winning party does not obtain the absolute majority? i) That the party winning the elections governs alone or ii) That the party winning the elections governs in coalition with other political forces”. It is true that the scenarios that these two questions cover are not exhaustive. It could be the case, for instance, that a coalition not including the winning party formed. However, the alternatives offered are consistent with the questions about preferred coalitions led by PSOE and PP if one or the other were the election winners, which are those used for the operationalization of the dependent variable regarding specific coalition preferences.

${ }^{11}$ Translated from Spanish. It is worth mentioning here that additionally the question incorporated a choice for a second best coalition (adding “and which would be your second preference?”). However, this information was not used here since we just want to look at the preferred coalition, and that is the one mentioned in the first place. Besides, many respondents fell into the don't know or don't answer category for the second choice.
} 
second question but substituting PSOE for PP, but not offering the respondent the bizarre possibility of a PP-IU coalition. ${ }^{12}$

It is true that the question explicitly asks for governmental coalitions. And it is also a fact that at the nationwide level Spain has never experienced one. It could be hence argued that the survey expects from respondents something that they are not well-equipped to do: evaluate their preferences toward an abstract construct which is so hypothetical that they have never seen it real. However, as argued above, there is first the significant coalition experience Spaniards have at the regional arena. Second, although there have been no coalitions in the national arena, one might rather safely extend the logic of preferences for governmental coalitions and think about preferences for legislative coalitions or inter-party agreements more generally. ${ }^{13}$ Given the number of minority governments Spain has had, this sort of agreements have been very prevalent.

For the analysis of the type of government generic preferences, the main independent variables are the standard ideological self-placement in a 0 to 10 left-right scale (Left-Right), and the selfplacement on the 0 to 10 axis measuring preferences for decentralization (Preferences for Decentralization). To differentiate among specific party voters, we have also included the variable Vote Recall in 2008 March $9^{\text {th }}$ elections in the form of different groups of dummies depending on the particular econometric model. ${ }^{14}$ Also, we control for the experience of voters regarding different types of governments by incorporating the Share (of legislatures) with SingleParty Majority Governments in the Autonomous Community, the Share of Single-Party Min., and the Share of Coalitions. We include the former in the analysis of the generic preference for single-party absolute majorities, whereas we incorporate the latter two in the analysis of the choice between a coalition vs. a single-party minority.

\footnotetext{
12 The alternatives with UPyD as a partner are dropped from the analyses. See footnote 7.

13 The term legislative coalition is used Laver and Schofield (1990) to refer to these inter-party legislative agreements to pass one or a series of laws in parliament.

${ }^{14}$ Translated from Spanish, the specific wording of the question is: "Could you tell me which political party you voted for in the last general elections in March 9, 2008?”.
} 
For the analysis of specific coalition preferences, the main independent variables measuring ideological proximity are Distance to Alternative (Left-Right) and Distance to Alternative (Preferences for Decentralization) measuring the absolute difference between the self-placement of the individual and the placement attributed by her to the coalition in the left-right and decentralization dimension, respectively. Since we do not have data on how voters locate coalitions spatially, we follow the same approach as graphically above and consider the placement of coalitions as a non-weighted average of the attributed values to the parties forming the coalition. ${ }^{15}$ In order to evaluate whether the effect of proximity in each dimension varies across individuals with different partisan interests, we also interact the Distance to Alternative variables with PID (Party $X$ ), which is a dummy capturing whether the interviewee sympathizes with party X. ${ }^{16}$ In certain analyses we also include the Vote Recall variables to identify which are the preferred coalitions for each group of voters specifically. Given the alternative-specific nature of some of these variables, we use a conditional logistic regression as a statistical technique.

Finally, in order to isolate the effect of our main explanatory variables, several additional controls are introduced both in the analysis of generic and specific coalition preferences. These are standard socio-demographic variables such as Gender (Female), Age, and level of Education dummies (none, primary, secondary, vocational training, mid-university, superior). Although all analyses are run controlling for these variables, the related estimates are not displayed in the tables for the sake of presentational simplicity. ${ }^{17}$

\footnotetext{
${ }^{15}$ These averages are clearly a very rough account of what would be the ideological position of each coalition. Any weighted average (e.g. by electoral or seat share), though, would create problems to differentiate between coalitions given the much larger size of the two main parties with respect to the others. In any case, from a rank-ordering perspective, the unweighted averages make sense.

${ }^{16}$ The concrete wording of the two questions involved was: i) "Some people consider themselves sympathizers of one political party, even though they may not always vote for it. Others, by contrast, do not express sympathy to any particular party. In general, would you consider yourself as sympathizer of any party?”; and ii) “Could you tell me which party that is?”. To build the dummy PID (REG.) we have considered identification with / sympathy for any of the regionalist parties that are represented in the Spanish parliament.

${ }^{17}$ They are available from the author upon request, though.
} 


\section{Results}

Table 2 displays the results of Spanish voters' preferences for (1) or against (0) single-party absolute majorities in parliament. ${ }^{18}$ The strongest effect is that of ideology, with left-wing voters being more inclined to dislike single-party majority governments compared to minority and coalition governments. Similarly, those more pro-decentralization tend to prefer the latter rather than the former. Also, voters that live in Autonomous Communities with a higher prevalence of single-party majority governments tend to prefer, on average, absolute majorities. Regarding different groups of voters, their preferences tend to go in line with the expectations, with IU, ERC, and PNV voters being generally unfavourable to single-party absolute majorities. PP voters, on the other hand, prefer the latter, while for PSOE voters the direction of the preference is not clear. Rather surprisingly, CiU voters are not clearly against single-party absolute majorities. Although it is clear that at the nationwide level a single-party absolute majority would leave this regionalist party aside, it is also true that CiU has traditionally formed single-party governments at the regional arena, and that may explain the emerging pattern here.

\section{[TABLE 2 ABOUT HERE]}

Table 3 presents the estimates for voters’ generic preferences for coalitions (1) relative to singleparty minority governments (0). ${ }^{19}$ Interestingly, ideological self-placement does not seem to matter in this particular dilemma, while party preferences only have explanatory power in a couple of cases. IU voters tend to prefer coalitions rather than single-party governments, while

\footnotetext{
${ }^{18}$ All analyses are corrected using a sampling weight for the territorial representativity of the survey that denotes the inverse of the probability that the observation is included because of the sampling design.

${ }^{19}$ Since the question on which this dependent variable is based is only asked to those that in the first place oppose single-party absolute majorities, the estimates in Table 5 may suffer from a sample selection bias. Consequently, we ran a heckman probit, where the selection equation determined the preference for non-absolute majorities and the outcome equation was the preference for coalitions vs. single-party minority cabinets. Nonetheless, the postestimation Wald tests never allowed the rejection of the null hypothesis of independence of equations. This is why we opted for the presentation of two separate equations for each model. Heckman probits are available from the author upon request.
} 
CiU voters show again a preference for monocolor governments. Also, we find that the more the autonomous community of the voter has been under the rule of single-party minority cabinets, the less likely it is that they support these governments and tend to prefer coalitions instead. As expected, in conclusion, we find less clear patterns for this dilemma as the uncertainty regarding which specific coalition would form is rather high.

\section{[TABLE 3 ABOUT HERE]}

Tables 4 and 5 present the conditional logit estimates to evaluate the effect of party preferences and ideological proximity in the left-right and decentralization axes on PSOE- and PP- led coalitions, respectively. Regarding the former, the first thing we see in Model 1 is that party preferences influence coalition preferences by and large in the expected directions. IU voters tend to prefer a PSOE-IU coalition, while the voters of regionalist parties largely prefer a PSOEREG. coalition, while their most disliked alternative would be a grand coalition between PSOE and PP (specially for PNV and ERC voters). PP voters seem to reject any alternative that does not include their party in the government (i.e. clear preference for a coalition PSOE-PP and against PSOE-IU and PSOE-REG). Interestingly, the voters of the formateur tend to like a PSOE-IU coalition and dislike the other two.

As for PP-led coalitions, an agreement between this party and the regionalists is preferred relative to a PP minority government by all voters, except, precisely by PP voters. On the other hand, a grand coalition led by the PP would be preferred by PSOE voters but not PP ones, while the voters of the regionalist PNV show an overt opposition to this coalition.

\section{[TABLE 4 ABOUT HERE]}

\section{[TABLE 5 ABOUT HERE]}

Regarding the ideological proximity arguments, it is clear that they play an important role in voters' coalition preferences. The farther they place the parties forming the coalition from their self-placement in the ideological space, the less likely is that alternative to be preferred. This is 
both for the left-right and decentralization dimensions (Models 2). A closer look to the coefficients reveals that coalition preferences are more sensitive to the distance in the left-right axis rather than in the decentralization one, both for PSOE- and PP-led coalitions. This would go in line the expectations stated in the third section of this paper and previous literature. Figure 2 illustrates this finding by showing the influence of ideological proximity (distance to alternative) in each axis on the conditional probability of the choice of the preferred coalition. ${ }^{20}$ The downward slopes of the solid lines (left-right dimension) are steeper than the dashed ones (decentralization dimension), although this is far clearer for the preferences about the coalitions led by PSOE.

\section{[FIGURE 2 ABOUT HERE]}

However, this general pattern varies notably if we examine different partisan attachments. The interactions in Models 3 show that PP sympathisers tend to place more emphasis in the left-right dimension (negative coefficient) rather than in the decentralization one to choose their preferred coalition. In the exact opposite direction, regionalists are much more sensitive to the dimension regarding the territorial organization of the state, while the placement in the left-right axis seems to be much less salient for them. Interestingly, IU partisans follow the general pattern in the case of PSOE-led coalitions (non-significant interactions in Table 4), but when PP is the formateur their coalition preferences seem to respond more to the decentralization dimension rather than the left-right one (Table 5). This probably has to do with their general aversion to a grand coalition PP-PSOE relative to an agreement between PP and regionalist parties. Finally, those identified with PSOE follow the general trend in their preferences for PP-led coalitions, but their choice of coalition partners when PSOE is the formateur seem to respond more or less equally to both spatial dimensions.

Figures 3 and 4 show the sensitivity of ideological proximity in the two dimensions for the different groups of partisans on the preferences of PSOE- and PP-led coalitions, respectively. As expected, most of the lines follow a downward trend. What is clearer is that those identified with PP seem not to care much about the decentralization dimension when they have to choose their

\footnotetext{
${ }^{20}$ Local polynomial smooth plots with confidence intervals, as in figures 4 and 5.
} 
preferred coalition. That is, they seem to accept coalitions that are far from themselves in this dimension, but are much more sensitive to deviations in the left-right axis. In sharp contrast, regionalists are more willing to allow farther apart coalitions in the left-right dimension, whereas decentralization preferences are much more salient for them when building their coalition priorities.

[FIGURE 3 ABOUT HERE]

[FIGURE 4 ABOUT HERE]

\section{Concluding Remarks}

This work has aimed at studying voters' preferences for coalitions using the particular case of Spain after 2008 elections. It has explored the coalition preferences of Spanish voters concentrating on the effect of party preferences and ideological proximity in the two traditional dimensions of political competition in the country for different groups of partisans.

We have first showed that Spanish voters' generic preferences for different types of cabinets are not only influenced by their party preferences, but also by their ideological placement in the leftright and decentralization axes, as well as by the experience they have with different types of cabinets in their Autonomous Community. The further to the right, the more likely the voter prefers a single-party majority government (even after controlling for vote choice), and the more pro-decentralization, the less likely. On the other hand, the preference between coalitions and single-party minorities seems to respond more to idiosyncratic reasons, less related to ideological and party preferences.

In our second set of analyses we have found that party preferences importantly determine specific coalition preferences (namely, support or opposition to governmental agreements between concrete parties), but ideological proximity to the coalition is perhaps even more important. Our empirical results have revealed that voters are more sensitive to proximity in the 
left-right dimension than in the decentralization axis for their coalition preferences. However, regionalist partisans are a notable exception, as they are much more willing to accept a distant coalition in the left-right axis as long as it is located closer in their more salient territorial dimension.

All in all, in Meffert et al.'s (2009) terms, we hope this study has taken a step forward toward knowing more about what are the determinants voters' coalition preferences and toward providing better explanations about their sources and origins.

\section{References}

AGUILAR, P. \& SÁNCHEZ-CUENCA, I. 2008. Performance or Representation: The Determinants of Voting in Complex Political Contexts. In: MARAVALL, J. M. \& SÁNCHEZ-CUENCA, I. (eds.) Controlling Governments: Voters, Institutions, and Accountability. Cambridge: Cambridge University Press.

BÄCK, H. \& ROSEMA, M. 2008. Government Formation and Strategic Voting in Multi-Party Systems: Voting for Coalitions in the Netherlands. Political Studies Association Annual Conference. Swansea, United Kingdom.

BARGSTED, M. A. \& KEDAR, O. 2009. Coalition-Targeted Duvergerian Voting: How Expectations Affect Voter Choice under Proportional Representation. American Journal of Political Science, 53, 307-323.

BLAIS, A., ALDRICH, J. H., INDRIDASON, I. H. \& LEVINE, R. 2006. Do Voters Vote for Government Coalitions? Testing Downs' Pessimistic Conclusion. Party Politics, 12, 691705.

DEBUS, M. 2009. Pre-electoral Commitments and Government Formation Public Choice, 138, 45-64.

GONZÁLEZ, R., MANZI, J., SAIZ, J. L., BREWER, M., TENAZOS-PINTO, P. D., TORRES, D., ARAVENA, M. T. \& ALDUNATE, N. 2008. Interparty Attitudes in Chile: Coalitions 
as Superordinate Social Identities. Political Psychology, 29, 93-118.

GSCHWEND, T. \& HOOGHE, M. 2008. Should I Stay or Should I Go? An Experimental Study on Voter Responses to Pre-Electoral Coalitions. European Journal of Political Research, 47, 556-577.

IRWIN, G. A. \& VAN HOLSTEYN, J. J. 2003. They Say It Can't Be Done? Strategic Voting in Multi-Party Proportional Systems: The Case of the Netherlands. Annual Meeting of the American Political Science Association. Philadelphia.

JOU, W. 2010. The impact of supporters' ideological preferences on parties' coalition choices: Evidence from New Zealand and Japan. Political Science, 62, 166-188.

KEDAR, O. 2005. When Moderate Voters Prefer Extreme Parties: Policy Balancing in Parliamentary Elections. American Political Science Review, 99, 185-199.

LAVER, M. J. \& SCHOFIELD, N. 1990. Multiparty government: the politics of coalition in Europe, Oxford, Oxford University Press.

MEFFERT, M. F. \& GSCHWEND, T. 2008. Strategic Coalition Voting: Evidence from Austria. Annual Meeting of the American Political Science Association. Boston.

MEFFERT, M. F., GSCHWEND, T. \& SCHÜTZE, N. 2009. Coalition Preferences in Multiparty Systems. Annual Conference of the International Society of Political Psychology. Dublin, Ireland.

MÜLleR, W. C. \& STROM, K. 1999. Policy, Office, or Votes? How Political Parties in Western Europe Make Hard Decisions, Cambridge, Cambridge University Press.

NORPOTH, H. 1980. Choosing A Coalition Partner: Mass Preferences and Elite Decisions in West Germany. Comparative Political Studies, 12, 424-440.

RENIU, J. M. 2001. ¿Merece la Pena Coaligarse? La Formación de Gobiernos Minoritarios en España, 1977-1996. Revista Española de Ciencia Política, 111-142.

RENIU, J. M. \& BERGMAN, T. 2003. Estrategias, Objetivos y Toma de Decisiones de los Partidos Políticos Españoles en la Formación de Gobiernos Estatales. Política y 
Sociedad, 40, 63-76.

STROM, K. 1984. Minority Governments in Parliamentary Democracies: The Rationality of Nonwinning Cabinet Solutions Comparative Political Studies, 17, 199-227.

STROM, K. 1990. Minority Government and Majority Rule, Cambridge, Cambridge University Press.

THURNER, P. W. \& PAPPI, F. U. 1999. Causes and Effects of Coalition Preferences in a Mixed-Member Proportional System. Arbeitspapiere - Mannheimer Zentrum für Europäische Sozialforschung. Mannheim: Universität Mannheim. 


\section{Tables and Figures}

TABLE 1: Specific Preferences for Coalitions (Expectations)

\begin{tabular}{ccc}
\hline & PSOE Formateur & PP Formateur \\
\hline IU Voters & PSOE-IU & PP-PSOE or PP-REG. \\
PSOE Voters & PSOE (Min.) & PP-PSOE \\
PP Voters & PSOE-PP & PP (Min.) \\
CiU Voters & PSOE-REG. & PP-REG. \\
ERC Voters & PSOE-REG. & PP-REG. or PP-PSOE \\
PNV Voters & PSOE-REG. & PP-REG. \\
\hline \hline
\end{tabular}


TABLE 2: Generic Preferences for Type of Government (Single-Party Abs. Maj.)

\begin{tabular}{|c|c|c|c|c|c|c|c|c|}
\hline & \multicolumn{2}{|c|}{ Model (1) } & \multicolumn{2}{|c|}{ Model (2) } & \multicolumn{2}{|c|}{ Model (3) } & \multicolumn{2}{|c|}{ Model (4) } \\
\hline & Coef. & S.E. & Coef. & S.E. & Coef. & S.E. & Coef. & S.E. \\
\hline Left-Right & $0.114^{\star \star \star}$ & $(0.017)$ & $0.089^{\star \star \star}$ & $(0.021)$ & $0.085^{\star \star \star}$ & $(0.020)$ & $0.079 \star \star \star$ & $(0.023)$ \\
\hline Preferences for Decentralization & $-0.039 * \star \star$ & $(0.013)$ & $-0.029^{\star *}$ & $(0.014)$ & $-0.028 * *$ & $(0.013)$ & $-0.029 * *$ & $(0.014)$ \\
\hline Share of Single-Party Maj. in the AC & $0.401 * \star \star$ & $(0.115)$ & $0.320^{\star *}$ & $(0.127)$ & $0.335^{\star \star \star}$ & $(0.120)$ & $0.397^{\star \star \star}$ & $(0.133)$ \\
\hline Vote Recall (All Dummies) & \multicolumn{2}{|c|}{ No } & \multicolumn{2}{|c|}{ Yes } & & & & \\
\hline Vote Recall (IU) & & & & & $-0.497^{\star *}$ & $(0.198)$ & $-0.515^{\star \star *}$ & $(0.193)$ \\
\hline Vote Recall (PSOE) & & & & & 0.007 & $(0.082)$ & Ref. & \\
\hline Vote Recall (PP) & & & & & $0.200^{*}$ & $(0.103)$ & $0.205^{*}$ & $(0.110)$ \\
\hline Vote Recall (CiU) & & & & & -0.201 & $(0.159)$ & -0.197 & $(0.160)$ \\
\hline Vote Recall (ERC) & & & & & $-0.629^{\star \star *}$ & $(0.218)$ & $-0.631^{* * *}$ & $(0.217)$ \\
\hline Vote Recall (PNV) & & & & & $-0.493^{\star \star *}$ & $(0.150)$ & $-0.468^{* \star *}$ & $(0.152)$ \\
\hline Vote Recall (Abstention) & & & & & & & 0.070 & $(0.104)$ \\
\hline Constant & -0.271 & $(0.245)$ & -0.278 & $(0.262)$ & -0.194 & $(0.255)$ & -0.253 & $(0.271)$ \\
\hline Observations & \multicolumn{2}{|c|}{2376} & \multicolumn{2}{|c|}{2189} & \multicolumn{2}{|c|}{2376} & \multicolumn{2}{|c|}{2020} \\
\hline Pseudo R2 & \multicolumn{2}{|c|}{0.059} & \multicolumn{2}{|c|}{0.072} & \multicolumn{2}{|c|}{0.067} & \multicolumn{2}{|c|}{0.072} \\
\hline
\end{tabular}

Estimates for Gender, Age, and Education variables, not displayed.

Robust standard errors in parentheses

${ }^{* * *} p<0.01,{ }^{* *} p<0.05,{ }^{*} p<0.1$ 
TABLE 3: Generic Preferences for Type of Government (Coalitions vs Single-Party Min.)

\begin{tabular}{|c|c|c|c|c|c|c|c|c|}
\hline & \multicolumn{2}{|c|}{ Model (1) } & \multicolumn{2}{|c|}{ Model (2) } & \multicolumn{2}{|c|}{ Model (3) } & \multicolumn{2}{|c|}{ Model (4) } \\
\hline & Coef. & S.E. & Coef. & S.E. & Coef. & S.E. & Coef. & S.E. \\
\hline Left-Right & -0.028 & $(0.027)$ & 0.009 & $(0.034)$ & 0.001 & $(0.032)$ & -0.005 & $(0.035)$ \\
\hline Preferences for Decentralization & -0.001 & $(0.020)$ & 0.000 & $(0.021)$ & -0.002 & $(0.020)$ & 0.000 & $(0.022)$ \\
\hline Share of Coalitions in the AC & -0.010 & $(0.203)$ & 0.037 & $(0.225)$ & 0.017 & $(0.210)$ & 0.021 & $(0.232)$ \\
\hline Share of Single-Party Min. in the $A C$ & $0.941^{\star \star \star}$ & $(0.348)$ & $1.070^{\star \star \star}$ & $(0.375)$ & $0.913^{\star \star}$ & $(0.357)$ & $1.183^{\star \star \star}$ & $(0.390)$ \\
\hline Vote Recall (All Dummies) & \multicolumn{2}{|c|}{ No } & \multicolumn{2}{|c|}{ Yes } & & & & \\
\hline Vote Recall (IU) & & & & & $0.569^{\star \star}$ & $(0.274)$ & $0.602^{* *}$ & $(0.268)$ \\
\hline Vote Recall (PSOE) & & & & & -0.030 & $(0.125)$ & Ref. & \\
\hline Vote Recall (PP) & & & & & -0.174 & $(0.173)$ & -0.124 & $(0.176)$ \\
\hline Vote Recall (CiU) & & & & & $-0.366^{*}$ & $(0.208)$ & $-0.358^{*}$ & $(0.211)$ \\
\hline Vote Recall (ERC) & & & & & 0.109 & $(0.248)$ & 0.108 & $(0.247)$ \\
\hline Vote Recall (PNV) & & & & & -0.025 & $(0.191)$ & -0.041 & $(0.196)$ \\
\hline Vote Recall (Abstention) & & & & & & & -0.216 & $(0.157)$ \\
\hline Constant & 0.511 & $(0.369)$ & 0.232 & $(0.391)$ & 0.379 & $(0.396)$ & 0.360 & $(0.407)$ \\
\hline Observations & \multicolumn{2}{|c|}{1385} & \multicolumn{2}{|c|}{1251} & \multicolumn{2}{|c|}{1385} & \multicolumn{2}{|c|}{1165} \\
\hline Pseudo R2 & \multicolumn{2}{|c|}{0.014} & \multicolumn{2}{|c|}{0.038} & \multicolumn{2}{|c|}{0.023} & \multicolumn{2}{|c|}{0.033} \\
\hline
\end{tabular}

Estimates for Gender, Age, and Education variables, not displayed.

Robust standard errors in parentheses

${ }^{* * *} p<0.01,{ }^{* *} p<0.05,{ }^{*} p<0.1$ 
TABLE 4: Conditional Logit Analysis (PSOE-led Coalitions)

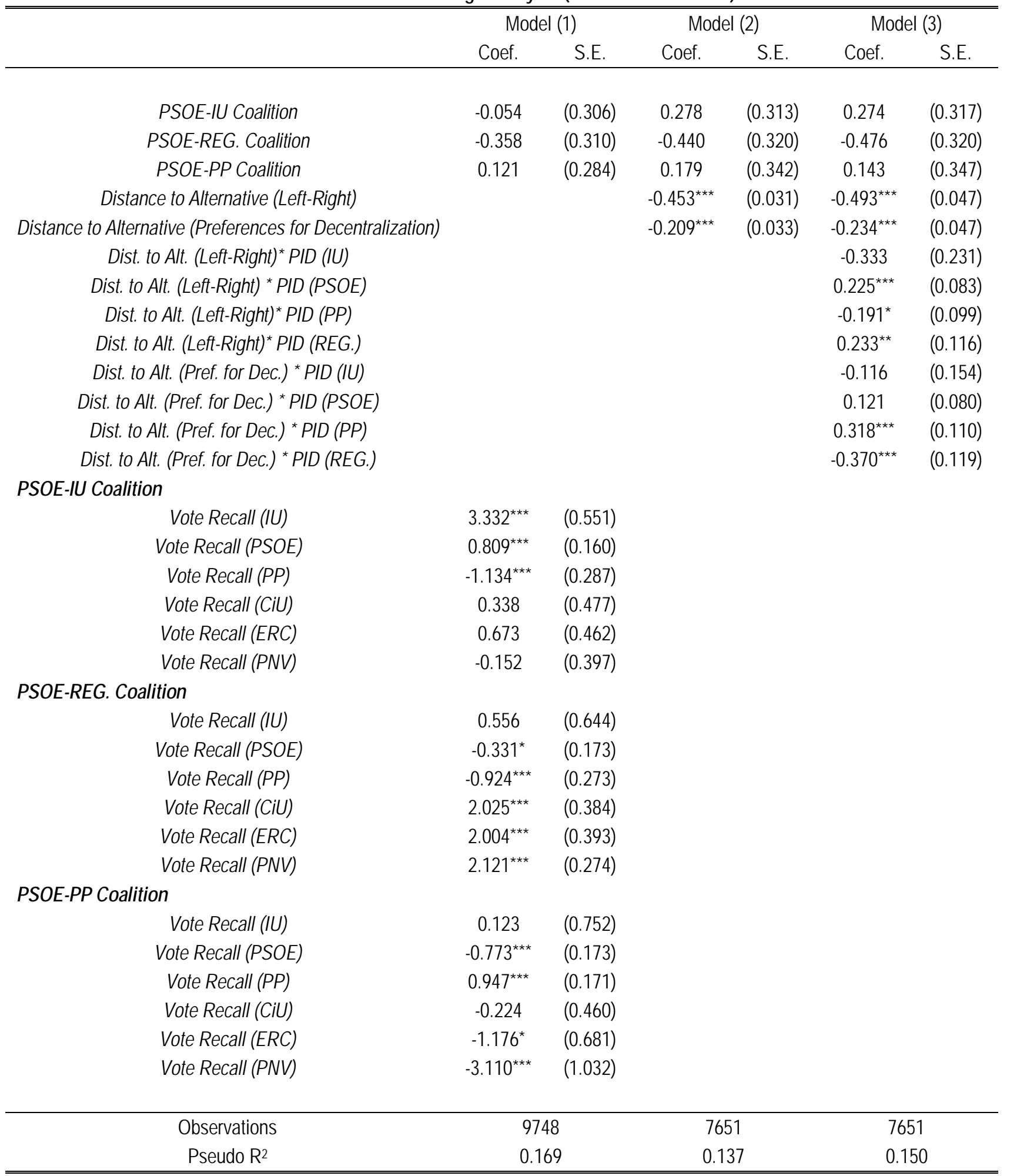

Estimates for Gender, Age, and Education variables, not displayed.

Robust standard errors in parentheses

${ }^{\star * \star} p<0.01,{ }^{*} p<0.05,{ }^{*} p<0.1$ 
TABLE 5: Conditional Logit Analysis (PP-led Coalitions)

\begin{tabular}{|c|c|c|c|c|c|c|}
\hline & \multicolumn{2}{|c|}{ Model (1) } & \multicolumn{2}{|c|}{ Model (2) } & \multicolumn{2}{|c|}{ Model (3) } \\
\hline & Coef. & S.E. & Coef. & S.E. & Coef. & S.E. \\
\hline PP-REG. Coalition & -0.260 & $(0.297)$ & -0.239 & $(0.298)$ & -0.258 & $(0.301)$ \\
\hline PP-PSOE Coalition & $0.521^{\star \star}$ & $(0.258)$ & 0.184 & $(0.284)$ & 0.233 & $(0.289)$ \\
\hline Distance to Alternative (Left-Right) & & & $-0.161^{\star \star *}$ & $(0.038)$ & $-0.128^{\star *}$ & $(0.055)$ \\
\hline Distance to Alternative (Preferences for Decentralization) & & & $-0.120^{\star \star *}$ & $(0.034)$ & $-0.143^{\star \star *}$ & $(0.049)$ \\
\hline Dist. to Alt. (Left-Right) ${ }^{\star} P I D(I U)$ & & & & & $0.304^{*}$ & $(0.172)$ \\
\hline Dist. to Alt. (Left-Right) * PID (PSOE) & & & & & -0.064 & $(0.079)$ \\
\hline Dist. to Alt. (Left-Right) ${ }^{\star} P I D(P P)$ & & & & & $-0.231^{* *}$ & $(0.115)$ \\
\hline Dist. to Alt. (Left-Right)* PID (REG.) & & & & & $0.442^{\star \star \star}$ & $(0.124)$ \\
\hline Dist. to Alt. (Pref. for Dec.) * PID (IU) & & & & & -0.112 & $(0.177)$ \\
\hline Dist. to Alt. (Pref. for Dec.) * PID (PSOE) & & & & & 0.086 & $(0.092)$ \\
\hline Dist. to Alt. (Pref. for Dec.) * PID (PP) & & & & & $0.210^{\star *}$ & $(0.092)$ \\
\hline Dist. to Alt. (Pref. for Dec.) * PID (REG.) & & & & & $-0.377^{\star \star *}$ & $(0.103)$ \\
\hline \multicolumn{7}{|l|}{ PP-REG. Coalition } \\
\hline Vote Recall (IU) & $1.392^{\star \star \star}$ & $(0.404)$ & & & & \\
\hline Vote Recall (PSOE) & $0.326^{*}$ & $(0.175)$ & & & & \\
\hline Vote Recall (PP) & $-1.328^{\star \star \star}$ & $(0.240)$ & & & & \\
\hline Vote Recall (CiU) & $1.727^{\star \star \star}$ & $(0.340)$ & & & & \\
\hline Vote Recall (ERC) & $1.582^{\star \star \star}$ & $(0.369)$ & & & & \\
\hline Vote Recall (PNV) & $1.337^{\star \star \star}$ & $(0.246)$ & & & & \\
\hline \multicolumn{7}{|l|}{ PP-PSOE Coalition } \\
\hline Vote Recall (IU) & 0.636 & $(0.397)$ & & & & \\
\hline Vote Recall (PSOE) & $0.486^{\star \star \star}$ & $(0.148)$ & & & & \\
\hline Vote Recall (PP) & $-0.377^{\star \star}$ & $(0.157)$ & & & & \\
\hline Vote Recall (CiU) & 0.210 & $(0.367)$ & & & & \\
\hline Vote Recall (ERC) & -0.210 & $(0.433)$ & & & & \\
\hline Vote Recall (PNV) & $-1.453^{\star \star \star}$ & $(0.389)$ & & & & \\
\hline Observations & \multicolumn{2}{|c|}{6273} & \multicolumn{2}{|c|}{4951} & \multicolumn{2}{|c|}{4951} \\
\hline Pseudo R2 & \multicolumn{2}{|c|}{0.110} & \multicolumn{2}{|c|}{0.070} & \multicolumn{2}{|c|}{0.080} \\
\hline
\end{tabular}

Estimates for Gender, Age, and Education variables, not displayed.

Robust standard errors in parentheses

${ }^{* * *} p<0.01,{ }^{* *} p<0.05,{ }^{*} p<0.1$ 
FIGURE 1: Party and Coalition Positions in a Two-Dimensional Space

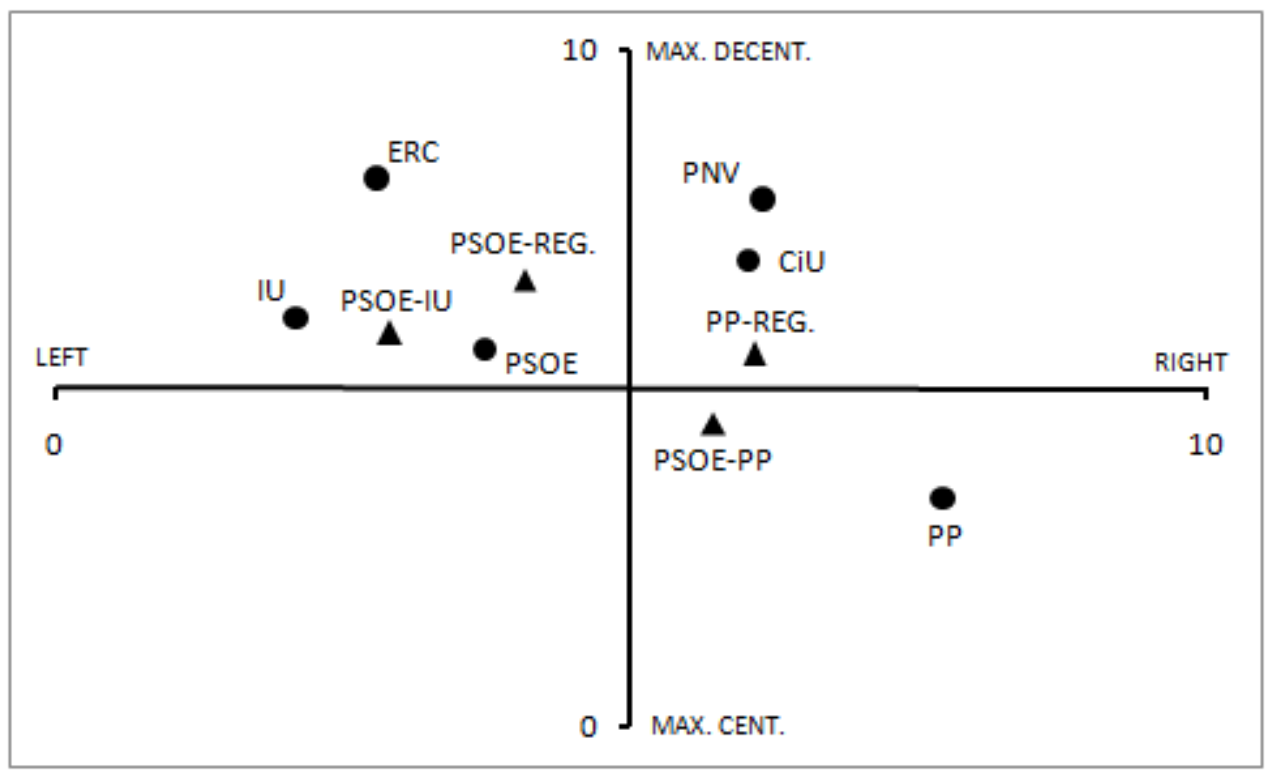


FIGURE 2: Ideological Proximity and Coalition Preferences (All individuals)
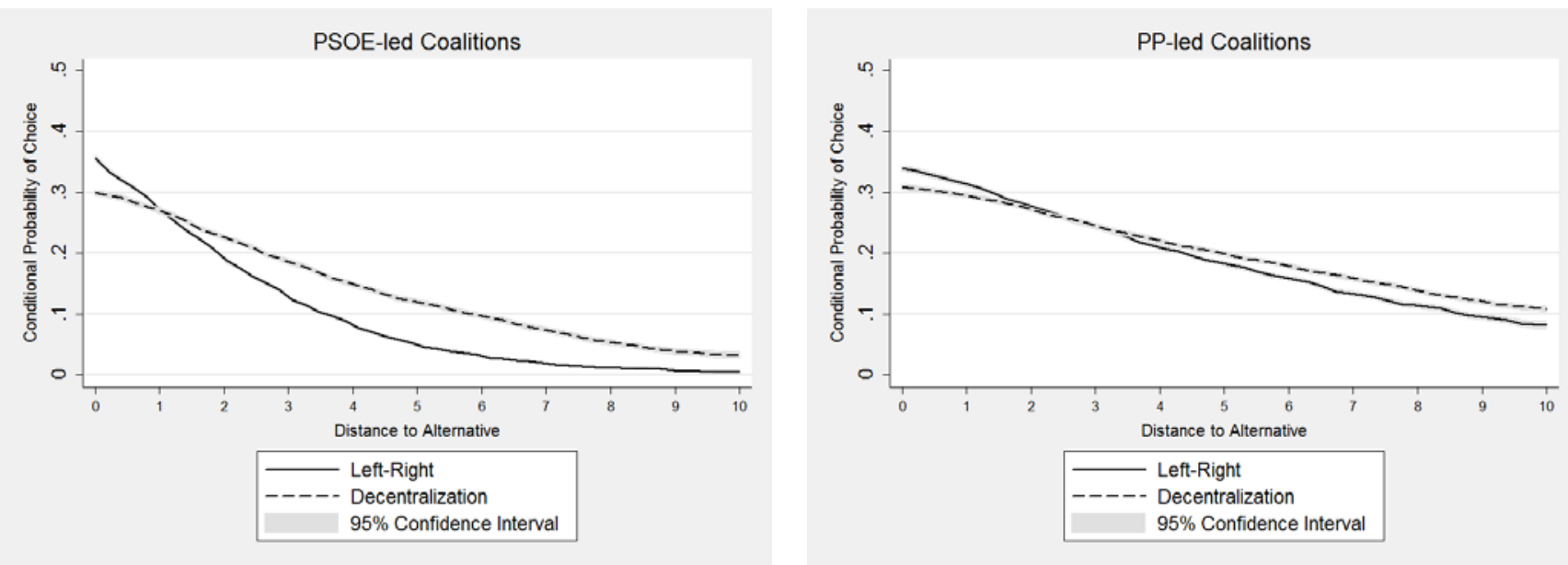
FIGURE 3: Ideological Proximity and PSOE-led Coalition Preferences (By partisan groups)
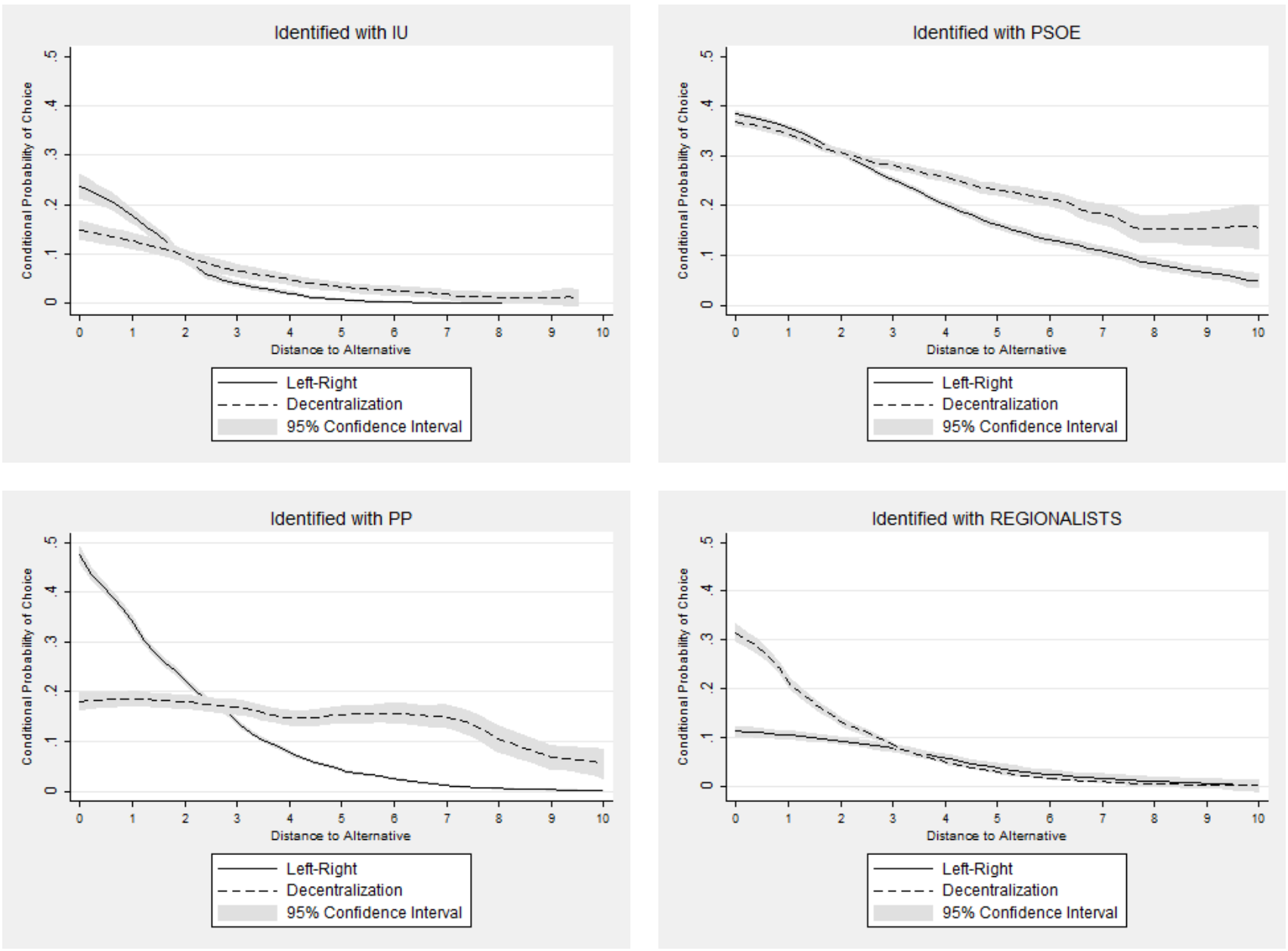
FIGURE 4: Ideological Proximity and PP-led Coalition Preferences (By partisan groups)
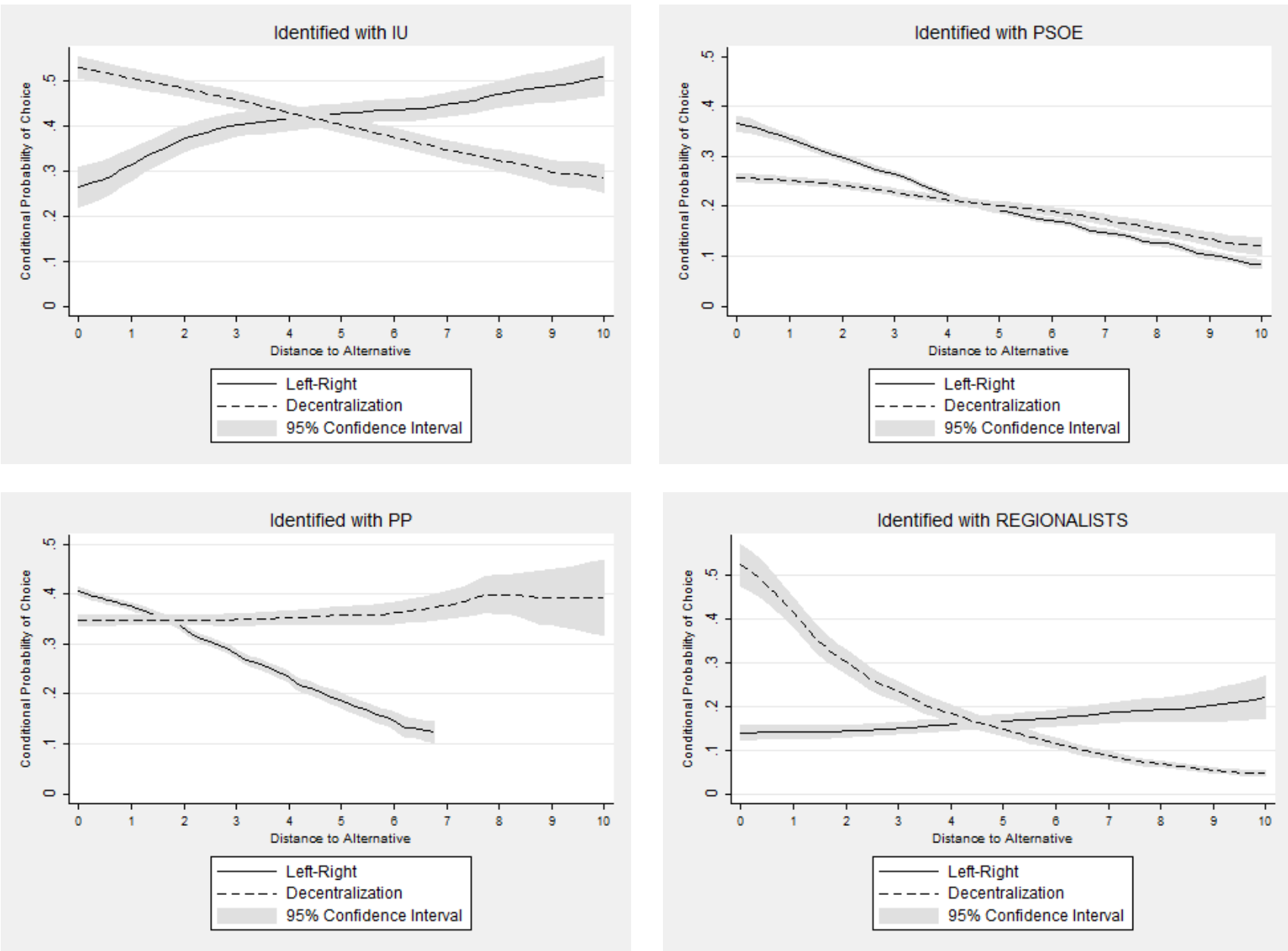